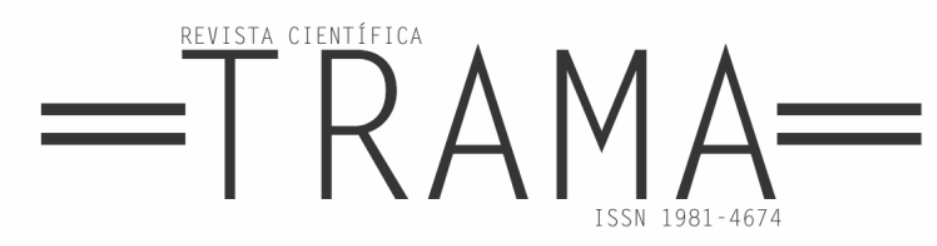

\title{
GOETHE: POETA E PSICANALISTA
}

\section{Ana Rosa Gonçalves de Paula Guimarães ${ }^{1}$}

RESUMO: O presente estudo objetiva evidenciar por quais maneiras o poeta préromântico alemão, Johann Wolfgang von Goethe influenciou os posteriores escritores do Romantismo, como também ensejou temas próprios à psicanálise fundada por Freud. Para isso, será feita uma breve descrição do Romantismo Alemão, para, posteriormente, analisar a construção do sujeito; o valor das vivências subjetivas; aos dualismos psíquicos e aos fenômenos de natureza inconsciente - tendo como eixo a questão de que Goethe foi psicanalista elou Freud foi romântico.

PALAVRAS-CHAVE: Goethe; psicanálise; romantismo; dualismos; subjetividade.

ABSTRACT: The present study aims to highlight in what ways the German pre-romantic poet Johann Wolfgang von Goethe influenced the later writers of Romanticism, but also gave rise to themes pertaining to psychoanalysis founded by Freud. For this, a brief description of German Romanticism will be made, to later analyze the construction of the subject; the value of subjective experiences; To psychic dualisms and to phenomena of an unconscious nature - having as its axis the question that Goethe was a psychoanalyst and / or Freud was romantic.

KEYWORDS: Goethe; psychoanalysis; romanticism; dualisms; subjectivity.

Contudo, por mais valioso que seja um experimento considerado individualmente, ele só adquire seu valor pela união e conexão com outros. Porém, justamente unificar e combinar dois experimentos que tenham alguma semelhança entre si exige, mas não na medida em que acreditamos.

Dois fenômenos podem parecer consecutivos um ao outro, embora entre eles devesse haver uma grande cadeia intermediária para levá-los a uma conexão verdadeiramente natural

(GOETHE, 2012, p. 59).

\footnotetext{
${ }^{1}$ Mestre em Psicologia com ênfase em Psicanálise e Cultura pela Universidade Federal de Uberlândia (UFU).
} 


\section{$=$ TRAMA $=$}

\section{INTRODUÇÃO}

O Sturm und Drang [Tempestade e Ímpeto] foi um movimento literário romântico alemão - o pré-romantismo situado no período entre 1760 e 1780. O movimento animava-se por uma reação ao racionalismo que o Iluminismo do século XVIII postulava. Os autores desse movimento defendiam uma poesia mística, selvagem, espontânea, quase primitiva, valorizando especialmente o efeito da emoção, imediato e poderoso, posto acima da razão. Os Stürmer eram contra a literatura e a sociedade do Antigo Regime. Deixando de lado a rígida métrica da poesia francesa divulgada em grande parte por Herder, voltaram-se, por exemplo, para a poesia de Homero, para a Bíblia Luterana, para os contos e histórias do folclore nacional nórdico.

Segundo os pressupostos dessa corrente romântica, o conflito entre indivíduo e sociedade não é totalmente analisado, objetivo que implica naturalmente no embate, não somente com determinada sociedade histórica, mas com a sociedade como tal, qualquer que seja. A incompatibilidade, porém, ao mesmo tempo o desejo de compreensão e reaproximação entre indivíduo e sociedade é o tema típico do Sturm und Drang e, de muitas correntes do Romantismo posteriores, tornando-se um dos motivos fundamentais do sentimento de Weltschmerz [dor do mundo], tão característico da época romântica.

Entre os representantes do movimento Sturm und Drang destacam-se Herder, Goethe e Schiller (Safranski, 2010). Os franceses, de acordo com as pesquisas de Carpeaux (1985), consideravam Goethe romântico, entretanto, para os alemães, Goethe é o maior dos classicistas. As duas partes apresentam igualmente argumentos para defender suas respectivas teses: o subjetivismo de Goethe é romântico, mas sua forma de expressão é 


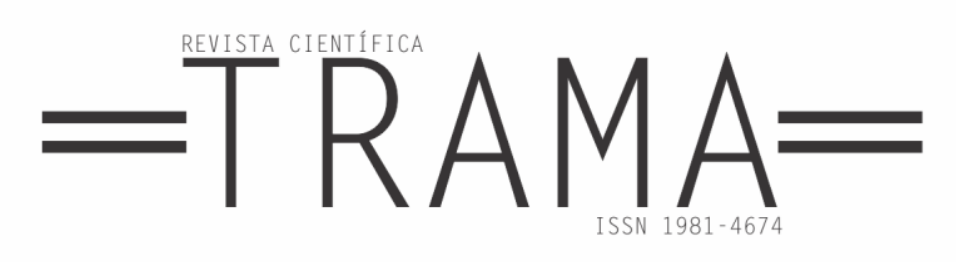

indubitavelmente clássica. Figura de destaque nos movimentos culturais Sturm und Drang e do Classicismo de Weimar, que buscava influência grega, Goethe foi a representação emblemática do nascimento do Romantismo em toda a Europa.

Johann Wolfgang von Goethe nasceu em 28 de agosto de 1740, em Frankfurt, na Alemanha, e veio a falecer em 22 de marco de 1832, em Weimar, localidade também alemã. Em Goethe, a linguagem e as tradições germânicas, de forma complexa, combinam-se, por meio de seu intelectualismo e da trama dramática de suas produções. Dentre suas principais obras, destacam-se: os romances Os sofrimentos do jovem Werther (1774), Os anos de aprendizagem de Wilhem Meister (1795-1796), As afinidades eletivas (1808) e as peças Fausto, Parte 1 (1808) e Fausto, Parte II (1832).

Habitualmente, o Romantismo, de acordo com Loureiro (2002), qualifica-se como um modo de pensar no qual se empregam e exploram os conflitos, as contradições e os choques entre os opostos, embora todas estas polaridades tendessem a ser resolvidas em uma síntese, sobre a qual o pano de fundo é uma unidade fundamental. A melhor definição de romântico, para Safranski (2010: 17), vem de Novalis: "Ao dar um sentido elevado ao comum, ao dar ao usual uma aparência misteriosa, ao conhecido a nobreza do desconhecido, ao fugaz uma aparência de eterno, assim é que os romantizo".

O estilo romântico para Loureiro (2002) pode ser definido por um sentimento de ruptura, o qual foi vivido como perda, ou ainda, para Andrade (2011), o movimento buscou a unidade perdida. Já Kiefer (1985) destaca o Romantismo como o rebaixamento corajoso ao universo das emoções e Vizziolli (1985) revela que o movimento liberou as camadas inconscientes da mente. O "programa" romântico, segundo Suzuki (1998), almeja pelo 


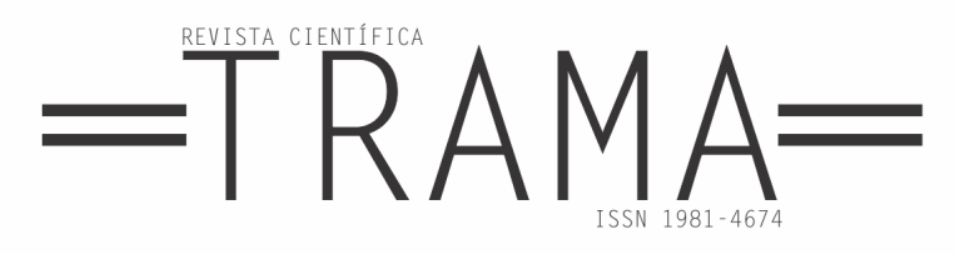

reencontro do sentido originário por meio da potencialização qualitativa da vida, ou seja, por exemplo, oferecer ao finito um brilho infinito, o que fez com que adquirisse uma expressão corriqueira - a filosofia romântica. A partir disso, percebe-se a multiplicidade dos tipos românticos, de modo a ser mais pertinente falar em "Romantismos", no plural, do que em "Romantismo".

\section{GOETHE PSICANALISTA E/OU FREUD ROMÂNTICO?}

A partir do século XVIII, foi possível observar uma redefinição das relações entre sujeito/objeto, tanto no plano da ação, quanto no plano do reconhecimento. A razão contemplativa, orientada para a verdade e concebida de modo receptivo de uma apreensão empírica ou racional acerca da essência das coisas, cede espaço, progressivamente, à razão e à ação instrumental.

De acordo com Figueiredo (2014), o sujeito empírico pode ser visto como um importante fator de erro e de ilusão, uma vez que a produção e a validação do conhecimento requerem o incremento do domínio técnico sobre a natureza, pressupondo, a partir disso, o autocontrole, a fiscalização e a autocorreção do sujeito, os quais se tornam o foco das preocupações epistemológicas e metodológicas, características de um projeto de psicologia como ciência natural do sujeito. Contudo, tal projeto envolve contradições: de um lado, sua natureza interna é útil à disciplina, devido ao método científico; porém, de outro lado, o objetivo deveria submeter-se às práticas da pesquisa - ao controle, o qual se desenvolve na interação com a natureza externa - seu caráter.

O sujeito é atravessado, portanto, por diversas rupturas, sendo de primeiro estado sua sensibilidade, afetividade e intuição, que conflitam com 


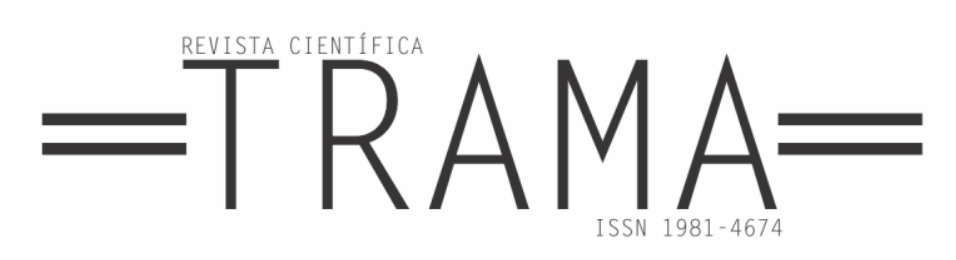

a razão instrumental. Em uma segunda esfera, a própria razão se abre às pretensões de um discurso racional, disfarçado de subjetividade. Além das rupturas próprias à subjetividade de cada um, o sujeito é em si dividido, por apresentar sua parte consciente e sua parte inconsciente. Ele é um "divíduo".

A perspectiva instrumental da administração racionalizada, dessa forma, apresenta-se como um projeto de ciência contra o sujeito, pelo fato de que há necessidade de se conhecer para fiscalizar, controlar, prever e corrigir os elementos irracionais. Todavia, um conceito, por exemplo, sobre o "bem" é individual e único, independente e irracional, sendo, portanto, inacessível às leis científicas e sociais. Desta perspectiva, a psicologia, para tanto, seria inviável, pois a ilusão transitória acerca do sujeito e do objeto não a justificaria enquanto uma ciência independente. Figueiredo (2014) refere-se ao projeto científico da psicologia como contendo as cisões pertinentes do indivíduo para si, do indivíduo para com o outro, assim como um suporte de papéis sociais predefinidos.

O sujeito é perpassado por algumas ideologias pertinentes a dado contex to que ele está inserido, como, por exemplo, destacam-se as ideologias científicas de dominação e as ideologias românticas. As ideologias científicas do pensamento psicológico afirmam que o sujeito é um objeto que se legitima o poder e a dominação. Já as ideologias românticas complementam que, além das questões acerca da dominação e do poder, a liberdade humana é indestrutível, em que o sujeito é livre e a própria escravidão seria uma opção do sujeito. Tais ideologias legitimam o isolamento do sujeito sobre si mesmo em um orgulho inconsequente de sua própria subjetividade. No entanto, todas as características que foram excluídas pelas matrizes cientificistas foram abarcadas na perspectiva intelectual chamada de vitalismo naturalista, em que o qualitativo, o 


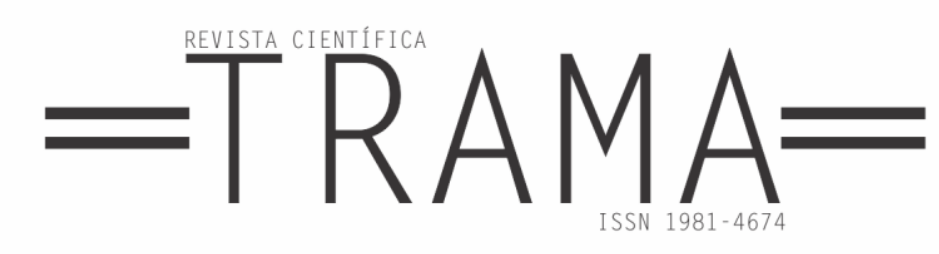

indeterminado, o criativo e o espiritual trocam-se em sinais. Contudo, ainda permanece a divisão entre a razão e a "vida".

As pesquisas de Figueiredo (2002) demonstram que o Romantismo pertence aos valores da espontaneidade impulsiva e, na medida em que a identidade é delimitada, as forças da natureza são transpostas. A potência dessas forças promove uma restauração do contato do homem com as origens pré-pessoais, pré-racionais e pré-civilizadas do "Eu", um contato com os elementos da animalidade e da infância. Essa Restauração propulsiona uma espécie de autodesenvolvimento, que, no entanto, é marcado por crises, experiências de desagregação, adoecimento, loucura e até mesmo de morte.

Figueiredo (2014) ainda destaca que Goethe percebeu a identificação entre sujeito e objeto e que, com o advento do Romantismo, houve um enfoque epistemológico mais adequado às possibilidades das ciências naturais. Nestas disciplinas, garante-se a supremacia da identidade entre sujeito e objeto e, simultaneamente, se instala o problema da comunicação e da interpretação.

Dessa forma, o Romantismo é antes de tudo uma filosofia da expressão, da representação simbólica, em que o resultado da intuição constitui-se pela superação da distância entre sujeito e objeto. Mais que uma relação sujeito/objeto: é o fruir da estética.

O século XIX não foi "romântico" apenas em sua primeira metade; ao longo de todos os seus decênios o seu orgulho cientificista, de aspecto sombrio e duro, pouco alegre e afável, salvo alguma trivialidade monística, foi compensado e mesmo superado pelo seu pessimismo, pela sua comunhão musical coma noite e com a morte, em virtude dos quais nós o amamos e o defendemos contra o desprezo com que o trata um presente de bem menor envergadura (Mann, 2015, p. 23).

O movimento estético em questão enuncia uma teoria do conhecimento, cujo $\mathrm{Eu}$ do sentimento como método subjetivo de 


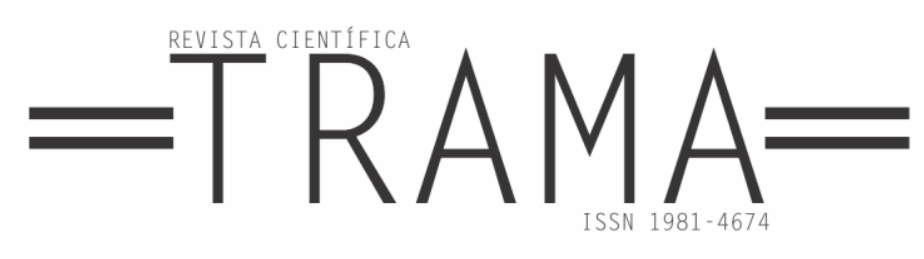

interpretação do mundo prevalece sobre o Eu da consciência da razão metafísica. A consciência romântica vem resistente também ao "eu" da cientificidade iluminista, que buscou reduzir o sujeito a um materialismo reducionista e a uma causalidade fenomenal. Nesse caso, a ciência não pode ser um modelo de verdade aplicado ao domínio humano. Lejarraga (2002) pontua que o Romantismo pode ser narrado como o primeiro grande protesto contra o mundo moderno, contra o materialismo e o cientificismo, ressaltando o predomínio do sentimento sobre o pensamento, do dinâmico sobre o estático e do orgânico sobre o mecânico.

Porém, quando Descartes focaliza a interferência da singularidade de um sujeito e de suas particularidades nas produções da racionalidade, seu gesto só faz ressaltar a importância mesma da subjetividade. Essa focalização da subjetividade como o que não se costuma à razão, ou como o que a confunda, abriu os canais para o movimento oposto ao da valorização da razão cartesiana: a ênfase na emoção, uma série de questões que causaram turbulência nas verdades e nos modos de viver estabelecidos, prenuncia a própria modernidade, com tudo que trouxe de novidade e subversão, e não apenas para os padrões tradicionais da Academia de Belas-Artes (MAURANO, 2003, p. 19).

Os românticos almejaram reconhecer todas as dimensões do ser, sendo ele constituído pelo sentimento, pela intuição, pela emoção e pelo afeto. Com isso, ansiavam pela exploração do domínio da interioridade humana em sua singularidade. No lugar de sofrer passivamente a lei da ordem física e moral instituída pelos administradores do território humano, a individualidade romântica é reconhecida como o ponto de origem de uma verdade. Cada homem, pela dotação originária que constitui sua personalidade, é chamado a desempenhar uma vida singular. O conhecimento de si, para os românticos, implica em uma passagem obrigatória pelos componentes da cultura. Eé por meio dessa passagem que será possível diferenciar as aquisições da época e as exigências próprias do sujeito. 


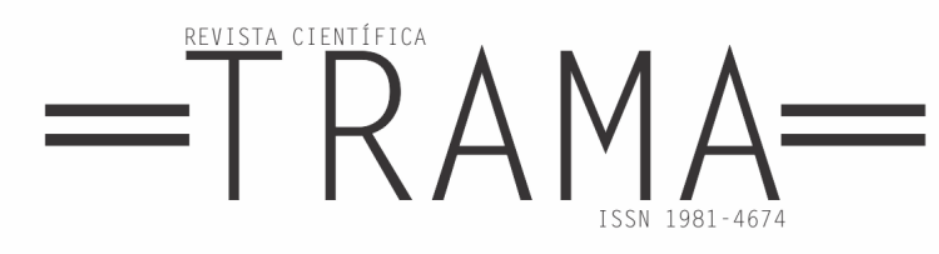

Um princípio vital inclui a probabilidade de multiplicação das mais simples origens dos fenômenos por meio do crescimento rumo ao infinito e às mais extremas diversificações. Um fenômeno em si e por si não é o suficiente. Ele necessita separar-se para assim poder se manifestar. Para Goethe (2012), todas as coisas existentes sofrem atuação da vida e podem ser pensadas através do dualismo. Destacam-se: "nós" e o objeto; a luz e a escuridão, o corpo e alma; duas almas; espírito e matéria; pensamento e expansão; sensibilidade e razão; fantasia e intelecto; ideal e real, ser e anseio. Em uma de suas cartas, Schiller ressalta, justamente, a questão dos dualismos analisados por Goethe:

O senhor deve ter tido uma certa fase, e não muito breve, que eu gostaria de denominar período analítico, quando, através da divisão e separação, o senhor ambicionou um todo, quando a sua natureza havia como que rompido consigo mesma e procurava restabelecer-se através da arte e da ciência (Goethe $\&$ Schiller, 2010, p. 52).

Há diversos dualismos na natureza humana, que foram inclusive evidenciados pelos românticos, porém, enquanto grande característica e aspiração do Romantismo, a polaridade universal que permite a natureza restabelecer ordem deriva de um equilíbrio, em virtude de um desequilíbrio permanente, no qual tal mecanismo encontra-se na base de todo o existente. A ambição romântica quanto ao postulado do absoluto, no entanto, propõe a recusa de todo dualismo e afirma haver um monismo ontológico e epistemológico.

Os românticos, entretanto, incapazes de se disciplinar em uma viagem sem fim, de acordo com Loureiro (2000), deixam grande parte das obras inacabadas, significando, com isso, fragmentos nostálgicos do infinito, o que se transformará em uma das próprias marcas do gênero romântico. A eterna inquietude, a busca infindável do Todo se torna, por isso, uma manifestação 


\section{$=$ TRAMA $=$}

do próprio sintoma da Sehnsuchtangst romântica, que se aproxima do objeto originário, objeto de angústia; a marca da própria falta, que pode impulsionar a pulsão do saber e o desenvolvimento do pensamento em direção à gênese de uma obra.

Da obra científico-poética de Goethe, os românticos herdaram, no plano ontológico, a noção de forma e a ideia da natureza como uma potência criadora e transformadora, dotada de uma temporalidade imanente. Os românticos resgataram e enfatizaram, portanto, o conceito de conflito entre as forças antagônicas como substrato dos fenômenos naturais. No plano epistemológico herdam, ainda, a identidade do sujeito com o seu objeto, que não deve ser desfeita pelos métodos objetivos das ciências naturais iluministas. Já no plano metodológico será o antielementarismo da apreensão globalizante das formas, o antimecanicismo das explicações dinâmicas da criação e das metamorfoses dos seres vivos e a evidência na experiência imediata, enquanto práticas científicas que ocuparão o centro das teorias românticas (Figueiredo, 2014).

Além de contribuir para a produção dos artistas românticos, Goethe não foi apenas o ideal cultural de Freud, mas foi o ideal para toda a cultura alemã, visto ser poeta, cientista, escrever sobre as cores e interessar-se pela paleontologia nascente. A influência da literatura na obra freudiana é uma constante, a qual é recorrida como fonte de conhecimento privilegiado do inconsciente ao lado daquele que lhe é fornecido pela clínica com seu pacientes.

Freud (1930/1996) em seu discurso por ter sido agraciado com o Prêmio Goethe, na ocasião, por estar em idade avançada, avisou que seria representado pela sua filha Anna.

Relata que Goethe não teria rejeitado a psicanálise como tantos de seus contemporâneos fizeram, porque, ainda segundo o psicanalista, o escritor 


\section{$=$ TRAMA $=$}

alemão estaria familiarizado com alguns dos pontos em comum do conhecimento psicanalítico, bem próximos de conceitos e propostas da literatura e o poeta ainda nutriria aceitação pela força dos primeiros laços afetivos das criaturas humanas. Freud, além do mais, ressalta que Goethe sempre teve Eros em alta consideração, que acompanhou as expressões primitivas do poeta, manifestações estas de modo não menos decisivos do que Platão o fez no passado remoto.

Segundo Bracco (2011), o Prêmio Goethe, ao contrário do que muitos acreditam, não é um prêmio literário. Além de muitos agraciados terem sido poetas e escritores, este prêmio contempla reconhecidas personalidades, cujos feitos são dignos de honrar a memória de Goethe. Goethe tornou-se um símbolo de reconhecimento e de afirmação, não apenas para os germanistas, mas para toda a cultura mundial. A honraria a Freud efetuou-se diante de sua criação do conhecimento psicanalítico, à sua qualidade de escritor e apreciador da estética e, especialmente, por suas virtudes e grandes méritos pessoais.

A temática entre a articulação da psicanálise fundada por Freud e do Romantismo Alemão tem sido objeto de interesse desde o período em que o referido psicanalista era vivo. As discussões sobre as possíveis afinidades entre as duas correntes de pensamento tiveram como "patrono" Thomas Mann, cujo qual não hesitava em inserir a psicanálise freudiana na linhagem dos pensadores românticos. As possibilidades desencadeadas por tais interrelacionamentos adviriam do interesse de Freud por temáticas que marcam a alma romântica, como, por exemplo, o sonho, a loucura, a morte. Entretanto, o próprio Freud e alguns outros estudiosos sobre o assunto não são unânimes quanto a tais aproximações.

Loureiro (2002) destaca a tentativa romântica de restituir uma experiência de plenitude e de absoluto, contudo, para o conhecimento 


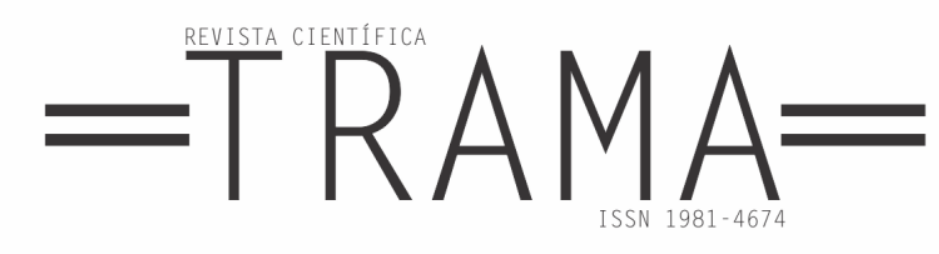

científico, Freud apontava os limites deste, a precariedade de seus alcances, a parcialidade e efemeridade de seus resultados, isto é, haveria a impossibilidade de um conhecimento totalizador. A autora (2002), em sua tese de doutorado, analisa algumas possíveis aproximações e afastamentos entre o Romantismo Alemão e a psicanálise. Contudo, conclui que o chamado "estilo romântico" na obra freudiana não partilha de uma nostalgia da plenitude perdida, nem intui pelo reencantamento do mundo.

Apesar disso, ainda, segundo Loureiro (2002), a psicanálise pode ser qualificada de anti-racionalista, já que sua busca dirige-se ao noturno, ao sonho, ao instinto, ao pré-racional, e a noção de inconsciente se inscreve em seus princípios. A obra freudiana contém referências a diversos autores românticos, como Hoffmann, Goethe, Schubert, Schelling e vários textos evidenciam o interesse do psicanalista por temas ligados também às tradições do ocultismo e do misticismo românticos, tais como: o duplo, a possessão demoníaca, a feitiçaria e a telepatia.

Anterior ao século XIX, o estudo sobre os sonhos atraiu a atenção de estudiosos, místicos e poetas. Porém, a abordagem dos sonhos era mais literária e metafísica do que experimental e científica. O escritor romântico alemão, Jean Paul fez experiências tentando reter a consciência e impor a vontade para controlá-los e, com isso, pode ter precipitado o interesse de Freud pela temática e aos possíveis significados latentes presentes no universo onírico.

Explorador das profundezas da alma e psicólogo das pulsões, Freud se inscreve na linhagem de escritores do século XIX e XX que - historiadores, filósofos, críticos ou arqueólogos - opõem-se ao racionalismo, ao intelectualismo, ao classicismo, em uma palavra, à fé no espírito do século XVIII e talvez mesmo um pouco do século XIX. Ele sublinhava o lado noturno da natureza e da alma, veem aí o fator verdadeiramente determinante e criador da vida, eles o cultivam e esclarecem-no por um viés científico; eles defendem, por meios revolucionários, a primazia de tudo o que é ctônico, anterior ao espírito, "vontade", paixão do 


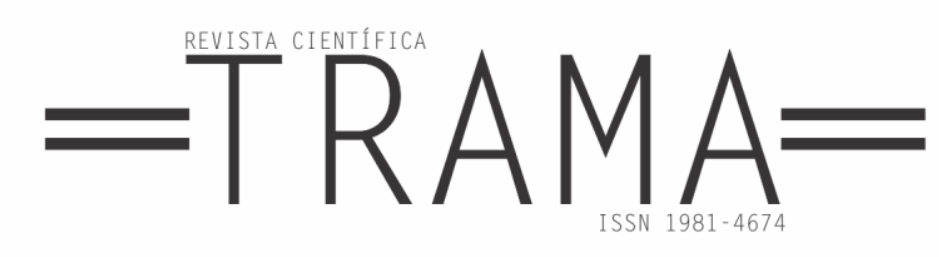

desconhecido ou, como diz Nietzsche, o "sentimento" primado sobre a "razão" (MANN, 2015, p. 19).

O inconsciente, para Mann (2015), poderia ser considerado, algum dia, como o efeito curativo que esses dois campos de conhecimento (a psicanálise e o Romantismo) têm para a humanidade, o qual corresponde a uma região da alma. Nela, a exploração e iluminação trouxeram enquanto conquista a missão do próprio espírito investigativo. Loureiro (2002) enfatiza que a psicanálise visa conduzir o desconhecido, o místico e o infinito às suas origens pulsionais, traduzindo-os em linguagem metapsicológica.

Como formações do inconsciente, os sonhos, atos falhos, fantasias, sintomas e chistes não obedecem às leis da racionalidade consciente, a qual exige coerência e clareza. O modo de funcionamento do inconsciente demonstra que o psiquismo é muito mais amplo do que o acessível à consciência. Além do mais, Maurano (2003) observa que a psicanálise ressalta que o Eu não é uma fachada do sujeito, todavia, constitui-se do que realmente escapa às suas possibilidades de apreensão.

O psíquico e o consciente eram pensados como instâncias que caminhavam juntas, pois, anterior às descobertas freudianas, os fenômenos da consciência eram conteúdos da alma e o psíquico inconsciente era algo inconcebível. Mann (2015) enfatiza a demonstração de Freud quanto ao psíquico, que abarca os conteúdos tanto conscientes, quanto inconscientes, pois o sujeito é cindido, dividido em si mesmo. A psicologia profunda e as descobertas de Freud sobre o inconsciente investem-se nos aspectos obscuros da natureza humana, as quais pertencem à história do espírito e ao conjunto de antagonismos das tendências mecanicistas e materialistas do século passado. Sendo assim, determinado fenômeno é interessante por ele mesmo, onde quer ele exista. No entanto, parte-se de um fundamento que ele exista enquanto uma finalidade. 


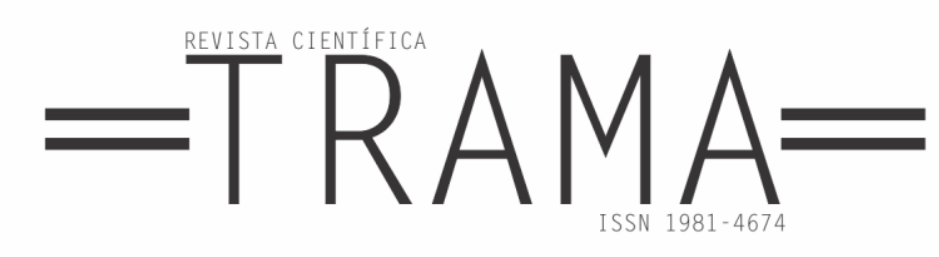

Ora, o psicólogo do inconsciente, Freud, é um filho autêntico do século dos Schopenhauers e dos Ibsens, em cuja metade ele nasceu. Como sua revolução está próxima da de Schopenhauer, pelos conteúdos, mas também pelo seu caráter moral. Sua descoberta do enorme papel que o inconsciente, o "isso", o "id", desempenha na vida psíquica do homem foi e é tão escandalosa para a psicologia clássica, segundo a qual consciência e vida psíquica são uma e mesma coisa, quanto a doutrina da vontade de Schopenhauer foi para toda crença filosófica na razão e no espírito (MANN, 2015, p. 60).

A grande iluminação trazida pelos românticos, de acordo com Sandler (2000a), foi a percepção do inconsciente. Também a noção de mundo interno e objeto internalizado foram elaborados entre o fim do século XVII e a metade do XVIII, época em que tais termos foram apresentados pela primeira vez, todavia, em um desenvolvimento posterior da mesma natureza de problemas - com o conhecimento psicanalítico cunhou-se os termos projeção e introjeção. Nesse contexto, foi introduzida a refutação da distinção entre um mundo interno e externo. Portanto, o cultivo de si e da interioridade, o autoconhecimento e a autonomia são características evidentes buscadas tanto em relação às propostas da psicanálise como pelo desejo romântico.

O Romantismo, contudo, confundiu emoções com sentimentos, pois os hipervalorizou violentamente. Na infância do movimento romântico, como na infância humana, a distinção entre realidade e ficção, verdade e alucinação tornou-se infactível. A busca do conhecimento encontrava um obstáculo talvez mais insuperável do que qualquer outro que já havia se deparado. O obstáculo, paradoxalmente, era também seu maior aliado: a emoção e a paixão. O Romantismo, para Sandler (2000a), tocou em um problema de limites tênues: o limite entre a alucinação e a realidade. Talvez se possa dizer que este é o marco inicial na história do Romantismo: o exagero e a polarização. 


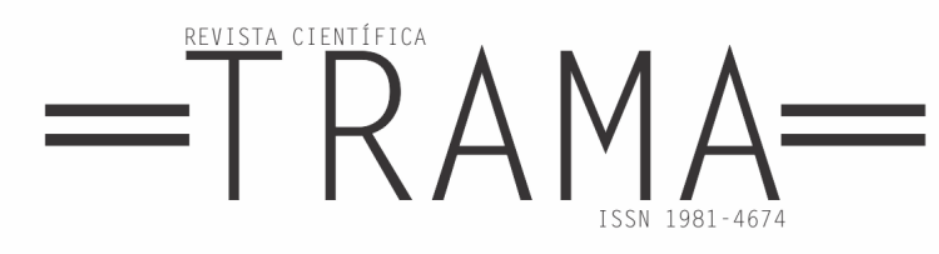

Esta seria a mente humana para o romântico: admiração incontida e incondicional por paixões fortes, sem pensar em consequiências de ódio e ressentimento. As histórias eram de amores aparentemente apaixonados, porém odiosamente destruídos; a dedicação total do outro, a uma causa (social-ista), implicava a própria morte e, portanto a falta absoluta; traições inexplicáveis, vinganças completas, ciúmes, remorso esmagador, desespero profundo e incontornável, falta de alternativas a não ser o orgulho ferido e a fúria frente à injustiça e à opressão; glorificação do militarismo; desprezo superior ante falhas humanas, como inveja, escravidão e covardia. (SANDLER, 2000a, p. 73).

Na vida psíquica existe a ilusão de que cada ser é único e original, representando, com isso, o seu caráter mítico. Para Mann (2015), o interesse mítico é natural à psicanálise, assim como o interesse psicológico é habitual ao trabalho literário. O recuo à infância da alma individual é ao mesmo tempo também o recuo à infância do ser humano, isto é, ao primitivo e ao mítico.

Por um lado, se o Romantismo tudo prevê, não há escapatória: até Freud, quem diria, acaba realizando em alguma medida os propósitos românticos. Por outro lado, porém, e aqui reside toda a diferença (se é que alguma diferença consegue resistir...), não esqueçamos que o estilo romântico é norteado pela ambição do absoluto. Todos os seus paradoxos e contradições, toda essa impressionante capacidade de fagocitar o que quer se lhe apresente, enfim, tudo isso é orientado pelo desejo último de síntese e de totalidade (LOUREIRO, 2002, p. 354).

Há vários dualismos na teoria de Freud, como, por exemplo, no nível da representação, percebe-se o dualismo de princípios (princípio de prazer e princípio de realidade); o dualismo tópico (inconsciente e préconsciente/consciente, processos primários e processos secundários) e, há ainda um dualismo energético (energia livre e energia ligada). No nível das pulsões, ocorre o dualismo entre as pulsões de vida e a pulsão de morte, em que se estabelece o dualismo entre as pulsões e as representações, ou seja, em linguagem mais precisa, entre o corpo e a alma.

Sandler (2001) afirma que Freud conseguiu perceber os dualismos do funcionamento psíquico tanto na possibilidade prática da realidade psíquica 


\section{$=$ TRAMA $=$}

quanto na formação da própria realidade psíquica, tornando o método de trabalho psicanalítico um movimento contínuo de tolerância de paradoxos. Há muitas manifestações de paradoxos observadas e vivenciadas pelo conhecimento psicanalítico: matéria $\leftrightarrow$ energia; sentimento $\leftrightarrow$ pensamento; pensar $\leftrightarrow$ fazer; teoria $\leftrightarrow$ prática; racionalismo $\leftrightarrow$ irracionalismo; análise $\leftrightarrow$ síntese; forma $\leftrightarrow$ conteúdo; consciente $\leftrightarrow$ inconsciente; isso $\leftrightarrow$ supereu; vida $\leftrightarrow$ morte; realidade $\leftrightarrow$ fantasia.

Os dualismos, com isso, fazem parte da metapsicologia freudiana. Tavares (2007), contudo, assinala que eles não seriam propriamente uma dialética, mas estariam caracterizados pelo próprio termo da "análise", isto é, são fundamentados com a quebra, a separação de elementos a fim de estabelecerem os conceitos enunciados.

Contudo, Figueiredo (2014) observa o totalitarismo do determinismo funcional da psicanálise freudiana, o qual atribui à decifração de sentido e uma identificação de intencionalidade dos conteúdos inconscientes. Todos os fenômenos psíquicos estão inter-relacionados. O sujeito é um todo cujas partes estão indissociáveis e as relações estabelecem um conjunto que tem função, estrutura e desenvolvimento. Como nada acontece ao acaso, "Freud explica", torna-se o retrato caricatural do determinismo absoluto de Freud. Entretanto, o determinismo absoluto freudiano não é determinista mecanicista, mas determinista funcional, porque a psicanálise freudiana acredita em uma explicação acerca da função de um sentido aos fenômenos psíquicos.

Em certo aspecto, no entanto, a psicanálise afasta-se das manifestações típicas do funcionalismo, em virtude de que exista a ênfase sobre a existência de um conflito. Por exemplo, a elucidação psicanalítica dos atos falhos evidencia que o homem é movido por tendências contraditórias muito mais frequentes do que se poderia supor. O conflito 


\section{$=$ TRAMA $=$}

entre forças pulsionais antagônicas, o embate entre as forças biológicas, as barreiras físicas, sociais e sua plena e imediata satisfação constituem e enfatizam um organismo funcionalista, em que a harmonia e a complementaridade entre as partes apresentam-se por meio de um sistema adaptativo. Com isso, as leituras puramente funcionalistas da psicanálise são apontadas como tendenciosas, pois eliminam o conflito como determinação essencial da vida psíquica.

A psicanálise visa conquistar, esclarecer e iluminar, isto é, tornar as "profundezas" e as "trevas" menos obscuras. Maurano (2003) refere-se ao conhecimento psicanalítico como tendo fundamentos à percepção da vida e do mundo, através de uma beleza que se movimenta e não se aquieta.

Assim sendo, Lejarraga (2002), em seus estudos, observa que Freud orientou-se pelo positivismo rumo à busca por causas fundantes, objetivas e universais. Entretanto, se tornou cada vez mais "romântico", principalmente na medida em que se abriu à inesgotabilidade das singularidades subjetiva: ao conceito de sujeito.

Os principais "transmissores" da tradição romântica - os autores chegam a empregar o termo "inoculação" - seriam os românticos tardios Fechner, Lipps e Fliess. Do primeiro, Freud teria recebido a topografia da mente, a idéia de uma cena do sonho, o princípio do prazer-desprazer, o da constância e a noção de repetição; de Theodor Lipps, extraiu elementos para sua teoria dos sonhos, do chiste e do inconsciente. Por fim, em Fliess estariam presentes alguns dos princípios básicos da biologia romântica (LOUREIRO, 2002, p. 48).

Os românticos também escolheram a noite como ambiente preferido de representação, o lugar de fusões, o ponto intermediário de sínteses, onde a vida retorna à unidade original. Para Andrade (2010), essa escolha se opõe à estética iluminada da Aufklärung: a luz do dia que separa, dissocia e torna o julgamento crítico possível. A escolha da noite, sobretudo, os Nachtstücke [noturnos ou literalmente pedaços da noite] literários que são identificados 


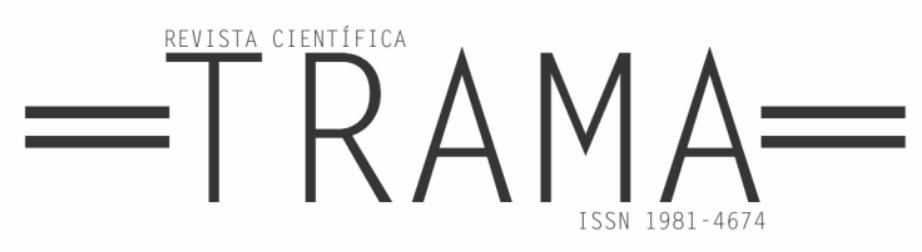

nos contos fantásticos de Hoffmann. Através da leitura do conto, Der Sandman [O homem de Areia], do escritor romântico alemão, E. T. A. Hoffmann, narrativa que levou Freud a escrever seu artigo: Das Unheimliche [O inquietante] (1919/2010), esse sentimento descrito pelo psicanalista é, portanto, o produto fundamental de análise do conto acerca do fenômeno do duplo e das manifestações derivadas do inconsciente.

Nesse sentido, as particularidades destacadas por Sandler (2000a) quanto à fronteira existente entre a psicanálise e a arte romântica apontam para o fato de que a humanidade foi introduzida na ciência por meio da medicina e esta foi inserida na arte pelos iluministas e românticos. Estas duas humanidades proveriam a ser apenas uma, vindo a se chamar "psicanálise". O movimento romântico, portanto, trouxe a consciência da necessidade de respeito e consideração para com a experiência emocional, visto que o idealismo alemão acabaria alastrando a ideia de que a mente humana tem uma capacidade sintética em si e por si mesma autonomamente.

Sendo assim, a consequência proporcionada por meio de tal movimento foi a psicanálise em si, proveniente da medicina e da ciência, a qual considerou a mente como seu instrumento, método e objeto de estudo.

\section{REFERÊNCIAS}

ANDRADE, R. A face noturna do pensamento freudiano: Freud e o Romantismo alemão. Niterói: EduFF, 2000.

BRACCO, M. O. K. Freud e o Prêmio Goethe. Jornal de Psicanálise. v. 44, nº 81, 2011. Disponível em: <http://pepsic.bvsalud.org/scielo.php?script=sci_arttext\&pid=S0103$58352011000200020>$ Acesso em 16 de ago. de 2017.

CARPEAUX, O. M. Prosa e Ficção do Romantismo. In: Guinsburg, J. (Org.). O Romantismo. São Paulo: Perspectiva, 1985.

FIGUEIREDO, L. C. M. A invenção do psicológico: quatro séculos de subjetivação (1500-1900). 6 ed. São Paulo: Escuta, 2012. 


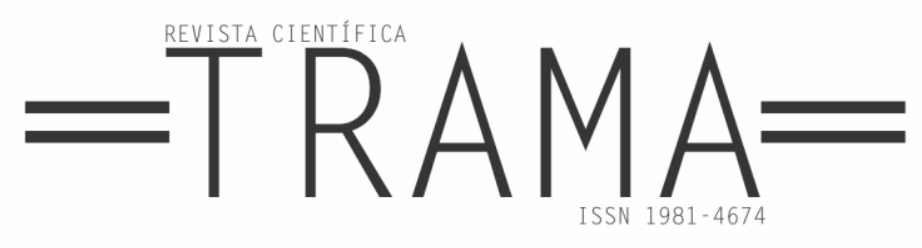

FIGUEIREDO, L. C. M. Matrizes do pensamento psicológico. Petrópolis, RJ: Vozes, 2014.

FREUD, S. (1996). O Prêmio Goethe (vol. XXI). In: ESB. Rio de Janeiro: Imago. (Trabalho original de 1930).

FREUD, S. (2010). O Inquietante. In: A inquietante História de uma neurose infantil (“O homem dos lobos"), além do princípio do prazer e outros textos (1917-1920). (P. C. Souza, trad.). São Paulo: Cia das Letras. (Trabalho original de 1919).

GOETHE, J. W. Ensaios científicos: uma metodologia para o estudo da natureza. (J. Cardoso, trad.), (A. J. Marques, apres. introd.). São Paulo: Barany Editora: Ad Verbum Editorial, 2012.

GOETHE, J. W. \& SCHILLER, J. C. F. Correspondência. (C. Cavalcanti, trad.). São Paulo:Hedra, 2010.

KIEFER, B. O Romantismo na Música. In: GUINSBURG, J. (Org.). O Romantismo. São Paulo: Perspectiva, 1985.

LEJARRAGA, A. L. Paixão e Ternura: um estudo sobre a noção de amor na obra freudiana. Rio de Janeiro: Relume Dumará; FAPERJ, 2002.

LOUREIRO, I. R. B. Freud e o estilo romântico. São Paulo: Escuta: FAPESP, 2012.

MANN, T. Pensadores modernos: Freud, Nietzsche, Wagner e Schopenhauer. (M. Suzuki, trad.). Rio de Janeiro: Zahar, 2015.

MAURANO, D. Para que serve a Psicanálise? Rio de Janeiro: Zahar, 2003.

SANDLER, P. C. A apreensão da realidade psíquica, volume II: Os primórdios do movimento romântico e a psicanálise. Rio de Janeiro: Imago, 2000.

SANDLER, P. C. A apreensão da realidade psíquica, volume V: Goethe e a Psicanálise. Rio de Janeiro: Imago, 2001.

SAFRANSKI, R. Romantismo: uma questão alemã. (R. Rios, trad.). São Paulo: Estação Liberdade, 2010.

SUZUKI, M. O Gênio Romântico: Crítica e História da Filosofia em Friedrich Schlegel. São Paulo: Iluminuras: FAPESP, 1998.

ROSENFELD, A. Texto/Contexto. 3 ed. São Paulo: Perspectiva, 1996.

TAVARES, P. H. M. B. Freud e Schnitzler: sonho, sujeito ao olhar. São Paulo: Annablume, 2007.

VIZZIOLLI, P. O Sentimento e a Razão nas Poéticas e na Poesia do Romantismo. In: GUINSBURG, J. (Org.). O Romantismo. São Paulo: Perspectiva, 1985. 